\title{
Ian Carter
}

\section{Is Analytical Action Theory Reductionist?}

\begin{abstract}
Steven Lukes and Alasdair Macintyre have accused analytical action theory of being motivated by reductionist aims and of ignoring the fact that what is distinctively human about actions is their essentially social character. These reductionist aims are said to 'subvert' the search for the distinctively human. Enterprises that have particularly come under fire (and which Lukes recommends 'abandoning') are the search for 'basic' actions and attempts to solve problems regarding the 'individuation' of actions. Lukes and Macintyre are mistaken however, both in their interpretation of the aims which motivate analytical action theory, and in their characterisation of the search for the distinctively human. 'Individuated' or 'basic' actions are not complex social actions reduced down to their 'simplest elements'. They represent attempts to resolve problems which arise prior to the examination of the social character of actions.
\end{abstract}

Critics of analytical philosophy have always been quick to point out that it is too abstract, individualist and reductionist. Yet in the field of action theory these criticisms have been levelled with such force by Alasdair MacIntyre (1981) and (especially) Steven Lukes (1985) that a defence against their claims seems particularly justified. For according to Lukes and MacIntyre, the proper aim of action theory is to throw light on what is distinctively human about action, while the tendency of analytical action theory to pose and answer questions in an "essentially reductionist" way has led it not only to detract from, but in fact to "subvert" that aim (Lukes 1985, 55-8). Lukes, indeed, goes as far as to suggest "abandoning" any enterprise which relies on ideas such as those of "basic" actions or of "individuating" actions, or which involves asking questions like "how are basic and non-basic acts related?" (Lukes 1985, 53). The guilty parties in question are not named by either Lukes or MacIntyre, but they must at least be taken to include Arthur Danto (1973), Donald Davidson (1980), Alvin Goldman (1970) and Irving Thalberg (1985). (Thalberg's article summarises recent developments in analytical action theory, and is seen by Lukes as itself "powerful testimony" to the "reductionist impulse" in contemporary analytical philosophy.) 
The "deep mistake" made by the above theorists, Lukes claims, is to assume that we can gain an understanding of the complexities of human action merely by reducing it down to "the simplest elements which make it up" (Lukes 1985, 53). Describing certain kinds of action as "basic", he says, does nothing to help explain those complexities; it only encourages "spurios notions of 'depth' ", and a mistaken tendency to regard such act descriptions "as fundamental - as identifying the bedrock and as explanatorily basic" (58).

MacIntyre also criticises the notion of "basic action", and goes on to ridicule philosophers who pose questions like "How do we individuate human actions?". For MacIntyre, "particular actions derive their character as parts of larger wholes", these wholes consisting in "narrative history"; it is "in the recipies of cookery books", and only in such places, that "actions are individuated in just the way that some analytical philosophers have supposed to be possible for all actions. 'Take six eggs ... Add flour, salt, sugar etc. ' " (MacIntyre 1981, 190-4)

How should action theorists search for the distinctively human? The answer, according to Lukes and MacIntyre, is to be found not in the notion of "an action", but rather, in that of "intelligibility". In order for action to be intelligible, we must have knowledge of its setting; of the concrete circumstances in which the agent acts, of his relationship with other humans, his past and possible future actions, and his intentions, both long and short term. Analytical action theory has ignored the distinctively human by being "insufficiently sensitive to the role of social context and history in rendering action intelligible", since "what is distinctively human is the social character of our actions" (Lukes 1985, 58).

Why cannot analyses of action which take into account its social context exist along side analyses which don't? Because, Lukes claims, the social context of actions is inseparable not only from the process of making them intelligible, but also from the very question of "what action is". "Consider how we come to identify a piece of behaviour as an action", Lukes says. We do this by seeing it as "falling under a description which makes sense of it to us", and if we are unable to make sense of it in this way, then "we have no reason to believe that we are dealing with an action" (Lukes 1985, 56; cf. MacIntyre 1981, 195). In arguing that to understand action in a social context is the same as to say "what action is", Lukes aims to cut the ground from under the analytical philosopher's feet. If he is right, there will be no space left for legitimate a-contextual investigations into the nature of human action.

The aim of this paper, however, is to show that Lukes is wrong. In fact, a fairer account of the aims of analytical action theory will show that Lukes and MacIntyre's critique rests on a "deep mistake" of its own. That deep mistake involves an unwarranted restriction of the scope of the search for the distinctively human. Such a restriction, moreover, leads inevitably to further errors, both about the sense, if any, in which analytical action theory can be correctly described as "reductionist", and about the very question of "what action is". 
Having argued that to make human behaviour intelligible is also to say "what action is", Lukes goes on to ask the question, "How, then, do we render intelligible action intelligible?" (56). This is rather like asking, "How can we make this stationary car stop?", or "How do you paint a blue wall blue?". In order to make this question intelligible we need more than the word "intelligible", and must distinguish between two levels of comprehension, the first of which is the recognition of actions capable of being understood, and the second of which is the understanding of them. (The Oxford English Dictionary defines "intelligible" as "capable of being understood".) Now since the first of these levels precedes the second, it cannot be that our knowledge of "what action is" consists merely in the second. If we can "make an action understood", we must have a prior notion of what it is to act. Indeed, Lukes and MacIntyre's distinction between "intelligible" and "unintelligible" action (MacIntyre 1981, 195) presupposes such a notion. ${ }^{1}$ When we come to identify a piece of empirical behaviour as an action we have already abstracted from our past understandings of human behaviour, and have already developed a concept of action; that is to say, we already have a definition of the word "action".

It follows, then, that there are two alternative ways of answering the question "What is action?". One way is to say "This is action", pointing to an empirical event and supplying justificatory evidence regarding its context and the motives and intentions behind it. The other way is to abstract from our experience of human and non-human behaviour in order to supply an account of action 'as such'.

It is this concept of action 'as such' which theories of basic action and act individuation have aimed to analyse. A basic action is an action which we do not perform by performing another action. An example of this 'by-relation' is where John kills George by shooting him. Why should we be interested in such a concept? Because, as Julia Annas puts it, "if there are human actions at all, and at least some actions are actions we perform by performing other actions, then there must be basic actions" (Annas 1977, 195). If this were not the case, then the byrelation could be traced back ad infinitum, which it cannot, if agents are to be seen as intervening at certain points in the causal chains which link the events of the world. The search for basic actions - for their location - is an attempt to define at exactly what point and in exactly what way the human agent intervenes. It is an attempt "to isolate ... the essence of action, to bring to a head there the question of the relation of an action with its reasons, motives and aims to the preceding and succeeding events with their causes and effects" (Baier 1971, 161).

1 Presumably, "unintelligible", here, means "not understood", rather than "incapable of being understood", since Lukes also claims that we have no reason to call "action", that which we cannot "in principle" understand (56). In this case, "intelligible" must mean "understood", and Lukes' question should have read: "How, then, do we render unintelligible action (action not understood, but capable of being understood) intelligible (understood)?" 
As such, it can be seen as an attempt to throw new light on the traditional philosophical problems of human agency, causation, free will and responsibility. (Though it is another question, whether or how far that attempt has succeeded.)

Act individuation is also concerned with these problems. We want to say that if a person 'acted' when he did $\mathrm{x}$, then there is a sense in which he was free to do $\mathrm{x}$, and that this freedom also implies his freedom not to do $\mathrm{x}$. But if $\mathrm{I}$ do $\mathrm{x}$ by doing $y$, in what sense was I free to do $x$, given that after I did $y$ I was not free not to do $x$ ? Is the answer "Only in so far as I was free to do $y$ "? In this case, is it a fact that all actions are basic actions, and that, as Davidson claims, "we never do more than move our bodies" (Davidson 1980, 59)? Or is every different act description a description of a different action (Goldman 1970, ch. 1)? If a basic and a non-basic action (brought about by it) are distinct, are they as distinct as two basic actions? How does the question of their distinctness bear on the question of degrees of responsibility for acting? Are we as responsible for what we do indirectly (by doing something else) as we are for what we do directly (see Prichard 1949, 19, cited in Baier 1971, 161)? We try to answer these questions in order to clarify the meaning and applicability of concepts (such as freedom and responsibility) which are normally used to refer exclusively to human behaviour.

What is more, in so far as we answer such questions we will, as Danto says, be clarifying what is universally human about action. And what is universally human cannot depend on particular contexts and social meanings, which are contingent factors. Nevertheless, this is not to say that Danto is unaware of the importance of contextual factors.

"One reason for this preoccupation with basic action ... is to be able to appreciate the points in the logical architecture of action at which those factors enter, through which the actions are converted into something more human and more social, and taken up into the fabric of communication, and deposited as part of human history." (Danto 1973, ix-x)

It is clear then, that if we are to criticise analytical action theory as involving "a loss in understanding and information as the process of abstraction is carried through" (Lukes 1985, 58), we must point to a loss in the understanding of factors other than those which concern the social meaning and explanation of action. In fact the reverse of Lukes' claim seems to be more true; that denying or ignoring the more abstract problems which arise out of the concept of human action involves a loss in understanding regarding the meaning of the concepts of freedom, agency and responsibility.

Can a concern with questions like those mentioned above ever be correctly characterized as 'reductionist'? Certainly not if we take Anthony Flew's definition of reductionism (given in his Dictionary of Philosophy). According to Flew, reductionism is "the belief that human behaviour can be reduced to or interpreted in terms of that of lower animals ... and ... ultimately to the physical laws controlling the behaviour of inanimate matter", and we have argued here, on the other hand, that analytical philosophers of action have been concerned with 
the nature of the distinction between human and non-human behaviour, and all of the philosophical perplexities which arise out of such a distinction. Yet the definition given by Flew would appear to be exactly that employed by Lukes, who, in characterising the reductionist position he criticises, points to the historical connection "between behaviourist reductionism and a strong positivist belief in the unity of the natural and social sciences". As an example he quotes Bernard Berelson, whose self-confessed "ultimate aim" is to "understand, explain and predict human behaviour" in the same way as scientists "understand, explain and predict the behaviour of physical forces or biological factors or ... of goods and prices in the economic market" (cited in Lukes 1985, 55). Lukes does concede that some theorists of action "have laid stress on the role of interpretation in ... the human ... sciences". But even this concession is one which need be made only to theorists other than those at whom Lukes is aiming his criticisms. Theorists of basic action and act individuation, as such, have neither denied nor been concerned with the role of interpretation in the human sciences.

MacIntyre's criticism of act individuation is similarly misdirected. It is simply not true that some analytical philosophers have tried to individuate actions in the same way as do the authors of cookery books. Act individuation, as philosophers of action address the problem, is about the nature of the causal relationship which exists between actions, and about the conditions, and implications, of any two or more actions being correctly described as numerically distinct. It has nothing to do with the understanding and explanation of particular sequences of actions whose numerical distinctness has already been assumed.

Perhaps a weaker sense can be given to "reductionism", such that it simply denotes the belief that two apparently different things can be identified with one another in terms of a single property which they hold in common. In this sense it could be said, for example, that Davidson has 'reduced' all action to basic action. But neither Davidson nor anyone else has claimed that in order to know everything about non-basic action, all we need to know about is the basic action which gives rise to it, as if action were in general composed wholly of basic actions. Basic actions are basic in a causal sense, but not in a compositional sense. To claim that we can 'reduce' action in the Davidsonian sense is quite different from claiming that to reduce all action down to the 'basic', individuated actions of individual humans is to gain an understanding of the complex nature of social action and its meaning, by explaining it in terms of 'the simplest elements that make it up'.

This point is best brought out by reference to a conceptual contrast which runs through Danto's book (1973); that between action and knowledge. For Danto, it is essential to the difference between actions and other events that action represents a restriction on our possible knowledge about human behaviour. To develop a theory of human action is to deny the claim that a complete understanding and explanation of human behaviour and its context implies, in principle, complete 
predictive power over it. In this sense, "where there is room for action there is none for knowledge; and where there is room for knowledge there is none for action" (Danto 1973, 26). Of course, this is not to say that Lukes and MacIntyre leave no room for the concept of action; there is no conflict between the concept of action and the kind of knowledge of human behaviour which they would prefer us to seek (as Lukes shows, in his criticism of Berelson). What is important, though, is that given this lack of conflict, it need neither be true that analytical action theory leaves no room for Lukes and MacIntyre's preferred kind of knowledge. And if that is so, then "The Contradictory Aims of Action Theory" (Lukes 1985) are compatible after all.

Just how mistaken are those who regard analytical action theory as in some sense 'fundamental'? We have seen that the theories developed by analytical philosophers of action do nothing to 'reduce away' knowledge about the social context of actions, and it would therefore be ridiculous to call them "explanatorily basic" (Lukes 1985, 58). But there is another sense in which the analytical aims of action theory are more fundamental than - because logically prior to - the contextualist aims, the pursuit of which presupposes either conscious or unconscious adherence to a particular analytical theory of action. Analytical action theory is required by any attempt to give a comprehensive account of the distinctively human. What Lukes and MacIntyre call the search for the distinctively human is in fact only a part of it.

\section{Bibliography}

Annas, J. (1977), How Basic are Basic Actions?, in: Proceedings of the Aristotelian Society $78,1977-78,195-213$

Baier, A. (1971), The Search for Basic Actions, in: American Philosophical Quarterly 8, $161-170$

Danto, A. (1973), Analytical Philosophy of Action, Cambridge

Davidson, D. (1980), Essays on Actions and Events, Oxford

Goldman, A.I. (1970), A Theory of Human Action, Englewood Cliffs/New Jersey

Lukes, S. (1985), The Contradictory Aims of Action Theory, in G. Seebass/R. Tuomela (eds.) Social Action, Dordrecht, 53-59

Prichard, H.A. (1949), Duty and Ignorance of Fact, in: Moral Obligation, New York, 1839

MacIntyre, A. (1981), After Virtue, London

Thalberg, I. (1985), Analytical Action Theory: Breakthroughs and Deadlocks, in: G. Seebass/R. Tuomela (eds.), Social Action, Dordrecht, 1-41 